\title{
The Application of Building Information Modelling in Landscape Design for Ecological Protection
}

\author{
Xilun $\mathrm{Cao}^{1, *}$, Ying Zhang ${ }^{2}$, Cheng Luo ${ }^{3}$ \\ ${ }^{1}$ Eco-civilisation Research Institute, China Urban Construction Design \& Research Institute Co., Ltd., Beijing, China \\ ${ }^{2}$ Department of Landscape and Forestry, Qingdao Agricultural University, Qingdao, China \\ ${ }^{3}$ Standardisation Technicall Committee on Heating-supply, China Urban Construction Design \& Research Institute Co., Ltd., Beijing, China
}

\begin{abstract}
Over the last decade, the widely use of Building Information Modelling (BIM) has significantly improved the efficiency of architectural, engineering, and construction (AEC) industry in China. Many studies have been dedicated to how BIM could help in construction works. However, due to lack of BIM application in landscape filed, limited researches could be found on how many excessive works could be prevented by BIM and its ecological value in protecting local environment, especially for those hillside areas with relatively vulnerable ecosystem, which covers over two thirds of the land in China. This paper aims to set up a BIM-based landscape design workflow and examine its effectiveness in reducing construction waste produced in design process. One project case of hillside residential district planning design was carried out by applying the established BIM workflow, showing that earthworks were reduced significantly, and the final net cut/fill volume was controlled at $32.45 \mathrm{~m} 3$ after project completion. Minimizing earthworks prevents the local topsoil and vegetation from been destroyed by unnecessary constructions. Utilizing BIM in landscape design enables the architects to pursue a more ecological and integrated design solution, paying more attention to the relationship between human beings and nature.
\end{abstract}

\section{Introduction}

\subsection{Background information}

According to the British Standards Institution, Building Information Modelling (BIM) is defined as a "digital representation of the physical and functional characteristics of a building over its life cycle" [1]. BIM integrates all the data and information related to the project or being created during AEC projects life cycle and presents them and their relationships in standardised and dynamically updated digital 3D models. It has significant advantage in cost control and collaborative work among project participants, and could be used not only for design, but also for calculating workload, simulating construction, project maintenance and so on.

As a country with substantial construction needs, China has rapidly spread BIM application in AEC industry over the last decade. According to China Construction Industry Association's BIM Application Analysis Report for Chinese Construction Enterprises (2019), nearly $80 \%$ of construction enterprises have applied BIM, with $57.82 \%$ of them having used it for more than 3 years [2]. From 2015 to 2020, BIM in China has also developed into in-depth level, showing its great advantage in resource integration and work collaboration in successfully constructing several mega engineering projects such as the Hong KongZhuhai-Macao Bridge, which makes significant cost- savings through prevention of error and unexpected changes at the early stage of the project.

Cost and quality control by BIM are also receiving increasing attention form Chinese researchers. Since many projects have large scales and long construction cycle, even the slightest inadvertence in design can result in substantial economic losses. Many previous studies are focused on evaluating construction quantities, tracking project costs, and integrating project information to achieve sustainable management and deliveries. Series of BIM-based software applications for further cost reduction have been developed as well [3].

\subsection{Research problem}

However, compared to building and municipal construction area, the landscape architecture is still at the exploration stage of BIM application in both practical and research field. From 2010 till now, several Chinese researchers have tried to apply BIM in various scenarios such as terrain modelling, planting design and crush check, and recognised that BIM could also benefit landscape industry in efficiency and effectiveness improvement [4]. Nevertheless, there is a lack of quantitative evidence to demonstrate how and to what extent BIM helped in those improvements by optimizing design solutions, and the following problems in current landscape design projects need to be solved by implementing digital technologies.

\footnotetext{
$\overline{\text { *Corresponding author: caoxilun@ }}$ cucd.cn
} 
Firstly, in traditional landscape design, because of the insufficient environment data as well as the technical limitations of $2 \mathrm{D}$ drawings, there is often difference between maps and the real terrain, which could cause errors in subsequent design and earthwork volume calculation, especially in areas with complex terrain. As a result, architects tend to carry out more site formation works to avoid the complexity of subsequent works, regardless of whether this is excessive or not according to local environment condition. However, extensive earthworks could lead to a significant increase in workload and project costs, and more importantly, they may damage local topsoil and vegetation, especially in ecologically fragile hillside areas.

Secondly, in the early stage of traditional design workflow, people are usually unable to obtain detailed information such as workload and cost estimation, therefore neither could they make comprehensive comparisons between different plans, nor adjust designs and check the effect timely. Ultimately, lots of design problems are not discovered until the late stage of the project, or even just before being delivered for construction. In addition, most of traditional design output are delivered by 2D drawings. Although a few of them may be presented by partial and static 3D models, it is still relatively difficult for nonprofessionals, such as project owners, to understand the design concept and design effect directly. The communication inconvenience leads to a negative impact on project quality and schedule, and extremely high cost of rework.

\subsection{Research objective}

On the bases of related researches carried out in the past decades, this paper aims to demonstrate the monetary and ecological value of BIM through exploring solutions to the above problems. The objective of this study is to examine the effectiveness of BIM in improving the ecological value of landscape design by providing scientific design solutions based on quantitative analysis, reducing excessive construction works, and raising working efficiency and visualisation level during the project life cycle. BIM integrates and analyses large sets of data and other project related fields, providing scientific guidance for people to make better decisions [5]. The architects no longer work solely based on their own experience and several standards or rules, instead they could have more in-depth understanding about the environment. BIM does not only provide quantitative data analysis to support designs, but also enable a more reliable perception about the cost and effect of the project, facilitating advanced necessary modification and improvement, controlling total cost, and creating more social and economic benefits. Only if a project design shows respect to the local environment and takes ecological effect into consideration at the very beginning of the project, the benefits it brings could be sustainable, including reducing the maintenance cost in the long run.

\section{Research method}

This research first establishes and applies a BIMbased landscape design workflow in one hillside residential district planning design case study, and then compares the earthwork volume between BIM and traditional design methods.

\subsection{BIM modelling software selection}

Autodesk Civil3D is used as the main platform in the case study. Civil 3D is an efficient BIM software widely applied in municipal infrastructure construction. It enables architects to generate 3D terrain quickly and accurately, and analyse spatial expressions such as elevation, slope, watershed area and so on. Since it creates dynamic correlations among different design elements, any design modifications could be updated simultaneously, which reduces the design workload significantly [6]. Therefore, when topographic data or design parameters changes, Civil 3D could also provide accurate earthwork volume and related cost calculations as well as detailed diagrams, allowing architects to optimise their solutions and make decisions based on those data.

\subsection{BIM workflow}

Based on the selected platform, a BIM workflow is established to help the architect complete works effectively by digital cooperative design tools. Unlike traditional workflow, there is no obvious distinction between design stages in a BIM workflow such as concept design or preliminary design. Instead, architects from various industries work on one single model simultaneously, to which information and design details are added and updated continuously.

\subsubsection{Information collection and terrain model construction}

The core value of BIM workflow is information flow. Before the design works begin, a comprehensive database is required to help the architect understand the design environment. To minimise ecological damage, environmental characteristics such as topography, sunlight, soil and hydrology should be carefully collected and classified in BIM software, and finally integrated to simulate an accurate digital terrain model, illustrating the actual situation of the construction site based on the collected information. These data, together with site drawings and field research information, becomes the basis for the following parametric analysis and planning design. 


\subsubsection{Quantitative analysis and design}

The constructed terrain model and related database provide quantitative support for deciding and modifying the design plans. For example, the architect could choose to display site information such as contour, slop, water flow direction and so on together in both 3D model and detailed tables. Any information added on this terrain model directly lead to changes in environmental data and will be updated in database and immediately presented in BIM model. Therefore, BIM assists architects to analyse the environmental influence of each design plans, compare the pros and cons between each plan, and finally make better decisions based on characteristics of the site and environment [7].

\subsubsection{Make modifications and calculations}

During the design process, modifications about design details could be made continuously according to any changes in the project, and those changes are immediately updated and automatically synchronised with both 3D models and 2D drawings. In traditional workflow, earthwork calculation, construction simulation and drawings delivery used to be repetitive and time-consuming, since scattered and isolated information often leads to rework for updates and corrections. In BIM workflow, data extracted digital model makes these works more convenient and accurate. Besides, while the project is about to deliver to construction, the architect can display a relatively reliable design effect of the work, reducing the gap between expectations and actual effect, and check if all the requirements have been satisfied

\section{BIM application case study}

The hillside residence district planning design project is located in north western suburbs of Beijing, which covers an area of $22.8 \mathrm{~km}^{2}$. The altitude is between $937 \mathrm{~m}$ and $979 \mathrm{~m}$ with a relative height difference of $42 \mathrm{~m}$. The application of the above BIM workflow is as follows:

Based on mapping drawings and field investigation data, the architect firstly modifies and inputs those data into Civil 3D, converts various forms of terrain data into 3D terrain with elevations, and then creates the Digital Elevation Model (DEM) of design site in BIM system as shown in Fig. 1. After the model has been generated it also needs to be checked and refined as necessary. Since Civil 3D is flexible to accept a wide range of data to create the terrain model, and its data is stored and processed in triangulated mesh mode for editing or computing, it provides more accurate design reference than traditional drawing software does. In addition, one could also adjust the coefficients for the different types of soil, thus setting corresponding rules for the earthwork calculation in advance.

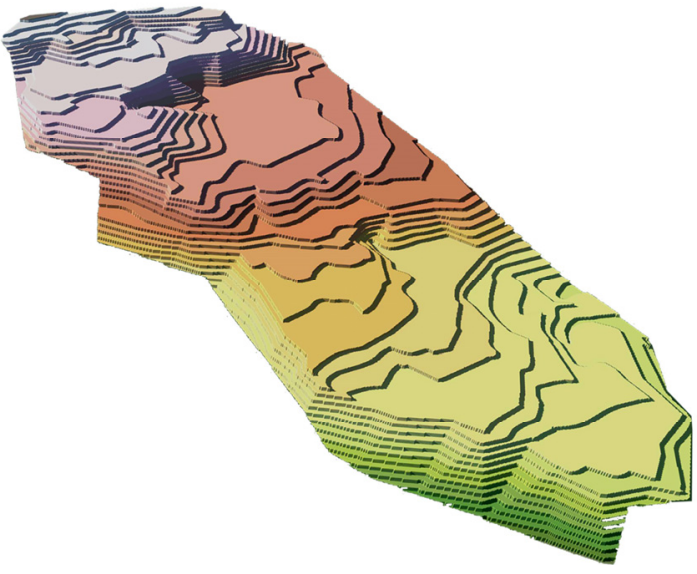

Fig. 1. DEM generated by elevation points

As the terrain surface model is generated, series of quantitative analysis of the surface properies could be carried out to support decision-making in planning design. In this case, the architects carefully process and examine the visualisation results of slope, catchment and other parameter analysis according to design regulations and other requirements as needed. For example, Fig. 2 shows the slope analysis result of the original terrain, attached with an automatically generated table summarizing minimum slope, maximum slope and sum of 2D area of this site (Table 1). Since areas with a slope higher than $25 \%$, which count for $39.6 \%$ of the total area, are protected from utilisation, designs are to be made upon $60.4 \%$ of the total area. Also, the drainage area analysis divides the terrain surface into different areas and displays information such as drainage boundaries and corresponding areas, making it easier for the architect to carry out subsequent drainage designs. The model presentations along with statistical tables enables subsequent design work such as road design to be more appropriate and efficient, and also provides reliable references for earthwork calculation later. As a result, the architect has a comprehensive understanding of the environment and more detailed considerations about design incorporated with nature at the early stage of the project.

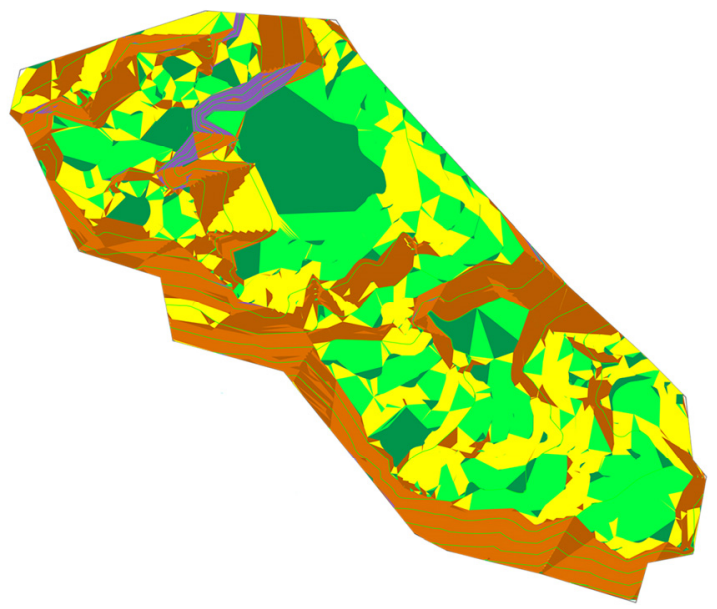

Fig. 2. A visualisation result of slope analysis 
Table 1. Slope and areas statistics

\begin{tabular}{|c|c|c|}
\hline Slope & Area $\left.\mathbf{( m}^{\mathbf{2}}\right)$ & Percentage \\
\hline$\leq 3 \%$ & 2703.59 & $11.8 \%$ \\
\hline $3 \%-10 \%$ & 5601.60 & $24.5 \%$ \\
\hline $10 \%-25 \%$ & 5510.62 & $24.1 \%$ \\
\hline $25 \%-50 \%$ & 4236.42 & $18.5 \%$ \\
\hline $50 \%-100 \%$ & 4106.46 & $18.0 \%$ \\
\hline$\geq 100 \%$ & 693.83 & $3.0 \%$ \\
\hline Total & 22857.52 & $100 \%$ \\
\hline
\end{tabular}

The powerful data processing capability of BIM helps architects to obtain more information during the design phase, which could be updated at any time and carried forward into the construction phase. Based on the analysis results, the architect could conduct designs directly on the terrain surface with related engineering data calculated automatically, which enables quantitative comparisons between different plans. Since each object with its information in BIM is dynamically connected to others, whenever any changes are made in design, the BIM model could be updated automatically, and related graphics and diagrams maintain consistent with the design solution, which not only improves work efficiency, but also reduces the chance of error occurring. Besides, one could also review the designs from different viewpoint and make modifications as needed, while the changes made could be synchronised to the information model.

Fig. 3 shows BIM building design in this case. Using slope grading function, the architect sets grading criteria and generates expected earthwork volume automatically. Based on this information, one could view the expected amount of cut and fill volume for current slope design plan, which could be modified by adjusting design factors such as elevations and grading measures. In this case, the total building area is $2,652.65 \mathrm{~m}^{2}$ with a slope under $10 \%$. The levelled land area is $2652.65 \mathrm{~m}^{2}$, with $740 \mathrm{~m}^{2}$ of excavation and $726 \mathrm{~m}^{2}$ of infill, giving a net cut/fill area of only $13 \mathrm{~m}^{2}$.

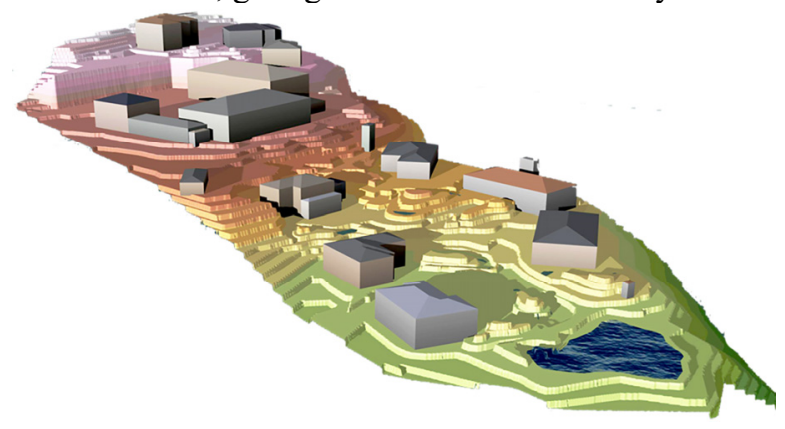

Fig. 3. Building design based on terrain surface

In road design, the architect could draw the road plan and road profile directly on the terrain model, then complete road assembly by selecting lanes, road shoulders and other components from Civil 3D's road component library, and finally create a road BIM model with graphics plotted as Fig. 4. At the same time, the earthwork volume calculation for road design could also be computed efficiently, enabling the architect to backfill the soil in the following landscape design., improving the efficiency of resource utilisation.

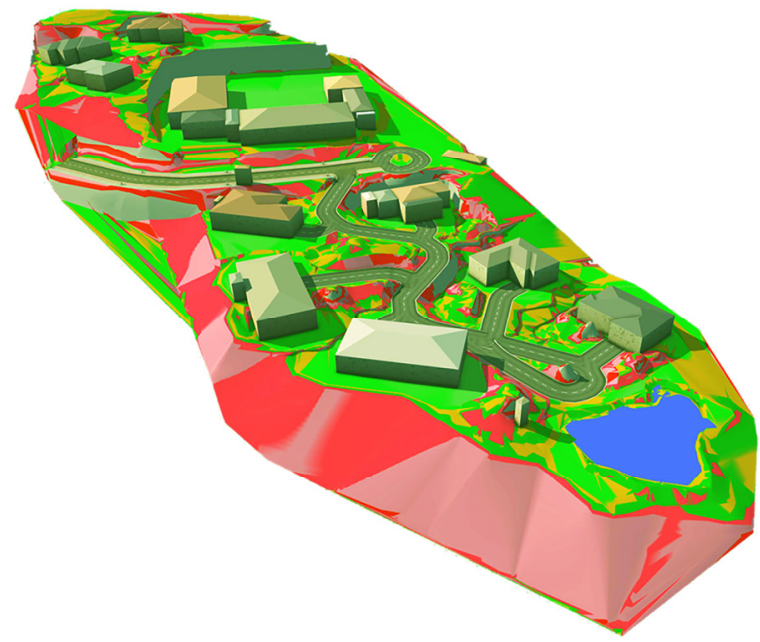

Fig. 4. BIM road design

The accuracy of earthwork volume calculations has a significant impact on project economic efficiency. Traditional calculation methods are usually based on calculus principles and might lead to greater errors when the terrain is complicated. In BIM workflow, the earthwork volume is automatically computed based on the elevation of original terrain and design model, and the effect after construction could also be simulated according to the design plan. The architect could check the earthwork volume for roads and site design with one click and adjust the plan according to the result to balance the cut and fill volume, reducing the damage to the environment. For example, according to simulation result, the differences between original terrain and design surface area of the preliminary design plan is estimated to be $7,763.98 \mathrm{~m}^{2}$, which is much higher than expectation and would cause great earthwork volume in construction, the architect then takes various measures such as replacing the retaining wall to modify the plan. After continuous adjustment and comparison, the surface area differences have been reduced to $653.45 \mathrm{~m}^{2}$ in the final design plan, and the detailed terrain surface area statistics for different levels of slope is shown in Table 2. According to the actual statistics in construction phase, the final cut/fill volume of this project is controlled at $32.45 \mathrm{~m}^{3}$, and the difference between estimated and actual volume of earthwork is only $17 \mathrm{~m}^{3}$, which is hardly to achieve using traditional design tools. The BIM model could also provide continuous support for construction, operation and management stages of the project.

Table 2. Surface area differences

\begin{tabular}{|c|c|c|c|}
\hline Slope & $\begin{array}{c}\text { Original } \\
\text { surface } \\
\text { area } \mathbf{( m}^{\mathbf{2}} \mathbf{)}\end{array}$ & $\begin{array}{c}\text { Design } \\
\text { surface } \\
\left.\text { area } \mathbf{( m}^{\mathbf{2}}\right)\end{array}$ & $\begin{array}{c}\text { Differences } \\
\mathbf{( m}^{\mathbf{2}} \mathbf{)}\end{array}$ \\
\hline$\leq 3 \%$ & 2703.59 & 5708.01 & +2703.60 \\
\hline $3 \%-10 \%$ & 5601.60 & 5192.46 & -408.54 \\
\hline $10 \%-25 \%$ & 5510.62 & 4219.00 & -1291.62 \\
\hline $25 \%-50 \%$ & 4236.42 & 2996.41 & -1240.01 \\
\hline
\end{tabular}




\begin{tabular}{|c|c|c|c|}
\hline $50 \%-100 \%$ & 4106.46 & 3926.91 & -179.55 \\
\hline$\geq 100 \%$ & 693.83 & 1766.40 & +1069.57 \\
\hline Net & & & +653.45 \\
\hline
\end{tabular}

\section{Conclusions}

This research summaries characteristics of BIM application in landscape in reducing excessive works and protecting local environment in ecologically fragile areas, establishes a BIM workflow and demonstrates it in one case study of hillside residential landscape design project, in order to examine to what extent BIM helps in improving design efficiency and minimising earthwork waste. With the assistance of BIM technology, the architect could accurately analyse environmental characteristics and optimise the design based on detailed and accurate data support. The result shows that when this project is completed, the net earthwork is controlled at a relatively low level, which protects the local environment from large-scale construction. Also, the BIM workflow built in this research enables the architect to optimise the design plans more effectively through quantitative data analysis and dynamically updated information model, which could provide references for landscape architects to apply in their practical works and find more ecological design solution in balancing human and nature benefits.

\section{Acknowledgements}

This research was funded by the Youth fund project of China Urban Construction Design \& Research
Institute Co. Ltd., grant number YQ69Y19410.

\section{References}

1. British Standards Institution. Briefing for design and construction. Code of practice for facilities management (Buildings infrastructure). (BIS, London, 2015)

2. China Construction Industry Association. China Construction Industry Association's BIM Application Analysis Report for Chinese Construction Enterprises. (CAB Press, Beijing, 2019)

3. Mohamed, R., Alwan, Z., McIntyre, L. BIM for sustainable project delivery: review paper and future development areas. ASR. 63(1):15-33 (2020)

4. Shu, B.L. et al. Research on Practice and Application of Landscape Information Modelling (LIM). CLA. 36(9): 23-28 (2020)

5. Zhu, C. et al. The application of BIM technology in landscape garden engineering projects. 1244 AISC, pp. 550-556 (2021)

6. Zhang, J.P. Digital civil engineering design: Autodesk Civil 3D. (CCI Press, Beijing, 2005)

7. Wei, X.., Bonenberg, W., Zhou, M. The Application of BIM in the "China Beautiful Rural" Design Project-Yangyou Village River Ecological Landscape Reconstruction Design Project. AISC 966, pp. 135-145 (2020) 